\title{
Translating Jinns in Naguib Mahfouz's Layali Alf Layla into English
}

\author{
BILAL ALDERBASHI \\ School of Humanities, \\ Universiti Sains Malaysia, Malaysia \\ bilalmohammad@student.usm.my \\ HASLINA HAROON \\ School of Humanities, \\ Universiti Sains Malaysia, Malaysia
}

\begin{abstract}
Jinns are an important part of Arabic culture and have been weaved into the texture of the Arabic language and literature; however, the overlap between the different classes of Jinns and the various interpretations of the entities mean that the translator is faced with the problem of non-equivalence when translating Jinns into another language. Taking this into account, the aim of this study is to determine the strategies used in the translation of four different classes of Jinns in Naguib Mahfouz's Layali Alf Layla into English. To conduct the study, the Arabic lexical items are extracted, listed, and described in the light of their cultural and linguistic background. Their counterparts in the English translation, Arabian Nights and Days, are also located and discussed, taking into consideration their cultural and linguistic background. The pairs are then compared in order to identify the relationships between the corresponding items and to examine the translation strategies employed. The strategies for dealing with non-equivalence as proposed by Baker (2018) are used as a framework for analysis. The results show that the translator employed the use of strategies such as translation by a cultural substitution, a related word, a less expressive word and omission when rendering the supernatural beings into English. The study concludes that understanding the nature of the Jinns in the source text and the different levels of meaning carried by each supernatural being can assist the translator in finding the most suitable equivalent in the target language for the different classes of Jinns.
\end{abstract}

Keywords: Jinn; Arabic literature; Naguib Mahfouz; literary translation; translation strategies

\section{INTRODUCTION}

George Steiner writes: "Without translation, we would be living in provinces bordering on silence". This statement explains why translators are considered as pioneers who struggle to cross these borders and bridge the gaps between languages and cultures in a process that "goes beyond transferring the meaning of words from one language into another" (Muhaidat \& Neimneh, 2011, p. 14).

One essential element of the Arabic culture that is firmly weaved into the texture of the Arabic language is the supernatural being known as Jinn. Jinns are mentioned repeatedly in old Arabic poetry, the narrations of the prophet Muhammad and the Holy Quran. They also represent a central component of the unseen realm in Islamic teachings. In spite of this, Jinns have generally been relegated to the margins where academic study is concerned. This point is underlined by El-Zein (2009), who explored the role of Jinns in Islam and in Arabic culture. She noted in her study that

people in the West currently are more interested to learn about jihad, the veil, the status of women in Islam, and the various fundamentalist movements. For them Islam is solely all of the above. They assume the Jinn is a topic better left to Disney and popular culture, or at best to anthropologists. Broadly speaking, many would argue this subject matter is very marginal, and would not add anything to the understanding of a religion such as Islam, while others assert its significance, but acknowledge at the same time it is a particularly thorny topic to address (El-Zein, 2009, p. ix). 
Trying to understand jinns also means trying to understand a very slippery concept in Islamic cosmology. A study focusing on jinns, however, could help in shedding light on an overshadowed and largely misinterpreted concept in the West. Additionally, tackling this topic may also help in addressing the paucity of research focusing on this cultural aspect (El-Zein, 2009 , pp. x- xi). The findings of the current study can thus draw attention to an important area of Islamic translation, which is interwoven in the texture of general, canonical, and, in the case of this study, literary texts.

Supernatural beings in the Islamic world can be categorised into several classes such as Jinn, Amer, Shaitan, Marid, Ifrit, Ghoul, Hinn, Nasnas, Shiqq and Si'lat (Al-Jahiz, 1965; ElZein, 2009). These classes, however, do not have clear-cut borders that differentiate one being from another. They can easily slip from one category into another, creating a state of uncertainty in terms of understanding and classifying these creatures (Duggan, 2016; El-Zein, 2009).

This ambiguity, however, enhances the employment of these creatures in different literary genres, such as movies, plays, short stories, and novels (Joshi, 2007). This is partly because such ambiguity can stretch the truth about these creatures and provide authors with more freedom to interpret the entity of these creatures and employ them in their literary works. Among the authors who have succeeded in integrating these creatures into the texture of their literary works is the Egyptian novelist, Naguib Mahfouz. In his novel Layali Alf Layla, Mahfouz presents Jinns as chief characters who play a significant role in twisting the plot of the novel. They interact with human characters in various ways that affect the course of actions in the novel. In addition to that, these mysterious creatures are employed in the novel to confront the reader with one of the most dialectic arguments regarding Jinns in the Arabic and Islamic worlds, which is, the true extent of the influence of Jinns on the deeds of men and whether they affect the actions of humans, or it is the "innate" evil in human nature that leads men to evil and madness (Ismail \& Ramadan, 2012).

The overlap between the different classes of Jinns, their profound impact on the Arabic culture, and the various interpretations of their real entities mean that in the context of translation, it is difficult to determine the exact lexical item that can be used to label each of those entities. The process of determining an appropriate equivalent term must therefore be conducted within the frame of cultural translation. The difficulties of translating the various classes of Jinns can be better understood if we take into account that even the process of transliterating these lexical items poses a challenge and usually results in various alternatives for the same entity (Caracciolo, 1988; Lebling, 2010). To further complicate the process of translation, both the East and the West have different perceptions of the Jinns. In most cases, the Arabs' understanding of the startling, troublesome, frightening creature has little to do with the promising, magical, unthreatening image of the same creature promoted among westerners by the media.

These issues have given rise to two different points of view where translation is concerned. On the one hand, some believe that there is no one translation strategy that is able to render the true meaning of Jinn (Colla, 2013). On the other hand, some others embrace the broader concept of untranslatability and seek guidance from available suggestions on dealing with non-equivalence.

A good mastery of the methods and strategies of literary translation is therefore required to overcome the problems that accompany the process of translating novels, which becomes more complicated when the translator is faced with the problem of translating lexical items related to entities that belong to the unseen realm of the Jinns in the Arabic and Islamic culture. Such lexical items, the meanings of which are derived from different semantic fields such as mythology, folklore and religion, pose a translation challenge that must be handled with utmost caution by the translator. In view of this, this paper aims at examining the translation of the 
different classes of Jinns from Arabic into English, focusing specifically on how they are rendered in the English translation of Naguib Mahfouz's novel, Layali Alf Layla.

\section{LITERATURE REVIEW}

\section{LITERARY TRANSLATION AND CULTURE}

Literature is considered as an artistic way of expressing meaning and conveying the beauty of language. Both language and literature have a strong connection that enriches cultural knowledge and creates a contextual form of the abstract imagination (Suliman, Md Yunus \& Mohd Nor, 2019).

Where literary translation is concerned, perhaps the most important aspect is the sustained effort to render the aesthetic value of the text since literary translation seeks to capture not only the meaning of its lexical items but also the aesthetic complexity of the source text (As-Safi, 2006; Kuhiwczak, 2003). This is partially because literary translation is an interdisciplinary process that goes beyond language to include literary tradition and culture (Allen, 2015). Such an interdisciplinary process is a kind of creative process that has to be conducted by a skilful translator, one who "is required to use his/her skills in applying a distinctive creative process that incorporates the linguistic structures and the cultural environment of the target language" (Al-Adwan \& Abuorabialedwan, 2019, p. 50).

The translator thus plays the role of not only a linguistic mediator but also a cultural interpreter. The translator thus has two primary roles to be carefully executed during the translation process. First, he is the recipient of the source text and must fully understand the explicit as well as the implicit messages of the original cultural content. Second, he is the message sender who must be able to find the best linguistic expression to render the cultural content of the source text (Ivir, 2003). In other words, the translator is responsible for understanding the relationship between the source language and culture before finding a suitable strategy to translate the source text into the target language.

The importance of the relationship between language and culture stems from the fact that both evolved together and influenced each other to create "homologous mental realities" in which a language marks the cultural identity (Guessabi, 2013, p. 226). In addition to that, language shapes the experience of the speaker by creating boundaries within the speaker's world (Lomas, 2018).

Even though "cultures are not isolated monads" (Lomas, 2018, p. 17), each culture still has its own peculiarities which differentiate it from other cultures. In every language, there are culturally "original words" that belong to a specific cultural background and have contextual nature of meaning (O'Neill, 2013, p. 218). Such lexical items pose problematic questions that need to be carefully addressed. Li (2019), who examined the influence of cultural differences on translation, states that the main differences between cultures are differences in values, customs and thinking modes. These cultural differences can cause severe problems and hinder the translation of a culture-laden text (Almanna \& Farghal, 2015, p. 152).

To overcome these obstacles, many scholars approach the translation of culture-bound terms from different perspectives. This includes the adoption of different approaches such as cultural transposition (Dickins, Hervey \& Higgins, 2017), domestication and foreignisation (Guessabi, 2013), and the Emic-Etic approach (Al-Masri, 2009; Almanna \& Farghal, 2015). It is also worth mentioning that to better understand cultural translation, the translator must keep in mind the broader sense of "cultural translation", in which "the prime cause of cultural translation is the movement of people (subjects) rather than the movement of texts (objects)" (Pym, 2010, p. 144). The same idea was hammered by Klankert (2014), who explained that 
cultural translation goes beyond texts to include the transferred material objects, concepts, knowledge, and practice.

\section{NON-EQUIVALENCE IN TRANSLATION}

Li (2019) suggests that cultural differences can also place significant obstacles in the path of translating literary texts, creating a state of non-equivalence between the source text and the target text. Jiang and Zhuang (2019) also point to cultural differences as one of the most important reasons for non-equivalence. Non-equivalence here is generally understood as the situation in which "the target language has no direct equivalence for a word which occurs in the source text" (Baker, 2018, p. 19). As such, the phenomenon of non-equivalence, the contributing factors of which are thoroughly discussed by Baker (2018), may give rise to problems that hinder the translation process.

It is impossible, according to Baker (2018), to offer a sound guideline to handle nonequivalence between languages. Types of equivalence can, however, be organised into specific categories to facilitate handling them. As will be discussed later, different strategies are suggested to overcome non-equivalence, considering that it is a widespread issue that is faced by any translator. Generally, the problem of non-equivalence

\footnotetext{
can be faced by the translator in various kinds of texts. It can be economic text, medical text, political text, and scientific text. Each kind of text has its own characteristic, which causes hardness for the translator to transfer the meaning. (Tarigan \& Juliana, 2019, p. 51)
}

Baker (2018) proposed the following eight strategies to overcome the problem of nonequivalence.

1) translation by a more general word (superordinate),

2) translation by a more neutral/less expressive word,

3) translation by cultural substitution,

4) translation by using a loan word or a loan word plus explanation,

5) translation by paraphrase using a related word,

6) translation by paraphrase using unrelated words,

7) translation by omission,

8) translation by illustration. (Baker, 2018, pp. 24-46)

These strategies, which are used as the framework for analysis in this study, are explained in the discussion of the examples later on.

\section{$J I N N$}

Supernatural entities exist in the Arab world long before the arrival of Islam. They vary in their impact on the life of the Arabs in different eras. Still, they significantly moulded part of the character and ideology of the Arabs and were embodied in a comprehensive system of idols, patrons, and mythical creatures. Islam rejects part of this system, accepts part of it, and modifies another part.

One of the best examples of supernatural creatures that played an extraordinary role in the religious, social, and psychological life of the Arabs before and after Islam is the Jinn. Jinns are intelligent free-will beings who can be good or evil (Peterson, 2007, p. 93). They were hailed in pre-Islamic Arabia as nature spirits or minor deities, but when Islam was revealed they were merely considered as part of Allah's creatures. They are mentioned in the holy book of Islam, the Quran, several times. In fact, there is a whole chapter in the Quran, i.e. Chapter 72 (Surah Al-Jinn) which carries their name. Jinns are said to have been created 
from smokeless fire or vapour (Campo, 2009). They are shapeshifter creatures that can take the shape of any human being or animal and can be visible or invisible.

The arrangement of these creatures into classes is based on different factors, such as their ability, their spiritual powers, their relationship to human beings, their similarities and dissimilarities with angels and animals, and their shape-shifting skills (El-Zein, 2009). Thus, different categories and classifications of Jinn can be found in Arabic and Islamic literature. Al-Jahiz (1965), in his book Kitab al-Hayawan ('Book of Animals'), divided Jinns into six classes: Jinn (the general term), Amer (the one who lives among people), Arwaah (the Jinn who troubles children), Shaitan (the wicked and malicious Jinn), Marid (the Jinn who is more vicious and malicious than Shaitan) and Ifrit (the strongest of all Jinns) (Al-Jahiz, 1965, p. 190). El-Zein (2009) elaborates on this classification by giving information about more categories of Jinn, such as the Ghoul, the Hinn, the Ifrit, the Marid, the Nasnas, the Shiqq, and the Si'lat. In short, there is no one definitive and accurate classification of Jinn that can be considered the only true and correct classification of these supernatural beings. However, the current paper analyses the four classes of Jinn found in Mahfouz's Layali Alf Layla, i.e. Ifrit, Satan, Iblis, and Marid. These four classes represent the most common and prominent classes which were discussed in significant traditional and modern resources such as Al-Jahiz (1965), Caracciolo (1988), Ibn Manzur (1999), Leeming (2004), Peterson (2007), El-Zein (2009), Lebling (2010) and Duggan (2016). These four classes were also mentioned in Quran, for example, Ifrit was mentioned in Chapter 27 (Surah $A n-N a m l$ ), verse 39, Satan in Chapter 6 (Surah Al-An'am), verse 112, Iblis in Chapter 2 (Surah Al-Baqara), verse 34, and Marid in Chapter 37 (Surah As-Saffat), verse 7. The analysis of these classes highlights the problematic equivalence issue and clarifies the different translation strategies used to render different classes of Jinn.

\section{NAGUIB MAHFOUZ'S LAYALI ALF LAYLA}

Mahfouz's Layali Alf Layla (1979), literally 'The Nights of Thousand Nights', was translated into English by Denys Johnson-Davies with the title Arabian Nights and Days (1995). The English translation was published in Egypt in 1995. The novel was short-listed in England for the Independent Prize for works of fiction in translation and was republished in 2005 by the highly prestigious "Limited Editions Club" in New York (Johnson-Davies, 2006). Even though the novel does not have the same popularity as other works of Mahfouz such as The Cairo Trilogy, it remains one of Mahfouz's most compelling translated novels. The course of events in this novel is directly affected by Jinns. Some of them were named as part of the novel's chief characters such as Qamqam, Singam, Sakhrabout and Zarmabaha. These characters are presented in the novel as Ifrits. However, other nameless characters that belong to other classes of Jinn such as Satan, Iblis, and Marid, are just referred to by their class since they play minor roles in the novel. It is worth mentioning that Arabic folklore is full of famous Jinns known by their proper names, for instance, Misihal, the Jinni of the famous Jahili poet, Al-A'sha; 'Amr, the Jinni of the famous Umayyad poet, Al-Farazdaq; and Khanzab, the Jinni who bothers Muslims while reciting Quran in prayers (Al-Jahiz, 1965).

Those Jinns play a vital role in the route of actions and impose a crucial question of the actual influence of Jinns on the actions of humans. Such characters may be familiar to readers of Mahfouz's novel since the novel is inspired by the original well-known folktale compilation, "One Thousand and One Nights", often referred to in English as "The Arabian Nights".

Mahfouz manages to embrace the manner and the style of the original folktale, taking advantage of the mythical and fantastic potentialities of the original (Al-Mousa, 1993). Mahfouz leans on the Jinn to create another level of analysis that depicts human psychology 
and supports the overall attempt of the novel to criticise the social and political aspects of his real world by relating it to the fictitious literary world. Mahfouz's Layali Alf Layla starts where the original "One Thousand and One Nights" ends. It follows the same episodic quality in which semi-independent stories connect and overlap (El-Enany, 2005). Just like the characters in the original tale, the characters in Layali Alf Layla represent different types and classes of people. The novel also introduces the Jinns as mysterious characters who affect the course of actions during the novel. In his novel, Mahfouz creates a corrupt world full of influential bad officials and oppressed people, like the world in which Mahfouz lived (Bahrawi, 2016; Hallengren, 2004). The same can be said about the Jinns in Mahfouz's novel, who can be good, bad, or swing between the two states. Thus, an understanding of the exact characteristics of each Jinn may help the translator to translate their various classes using appropriate equivalents that create similar effects and facilitate the readers' understanding of the novel.

\section{TRANSLATING JINNS IN MAHFOUZ'S LAYALI ALF LAYLA}

The process of translating the different classes of Jinn must not be conducted in isolation from its cultural surroundings. It must, therefore, be analysed within the scope of culture. It must also be preceded by a thorough investigation of the lexical background of the word Jinn. Lexically, the word Jinn can be traced back to Aramaic-speaking Christians who used the term "to designate pagan gods reduced to the status of demons" (Henninger, 2017, p. 115). Ibn Manzur (1999), however, furnishes, in his well-known Arabic dictionary Lisan al-Arab ("The Tongue of the Arabs'), a detailed discussion of the word Jinn "جِّ". He discusses its root and various meanings, which revolve basically around the essence of hiding, being concealed or not being seen. For instance, the word Janeen "جنين" ('foetus') is derived from the root" "نं(j-n-n), since it is hidden in the mother's womb. The word janaan "جَنان" ('heart') is also derived from the same root since the heart is concealed in the chest of the human being (Ibn Manzur, 1999, pp. 701-706). The lexical item for the supernatural creature is al-Jinn "الجن", which means those who are concealed and cannot be seen by humans. The plural forms are

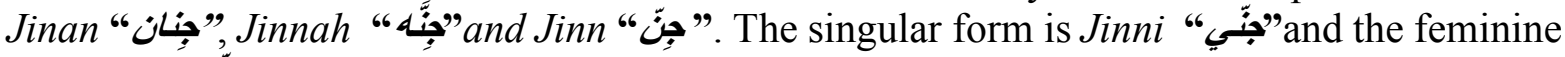

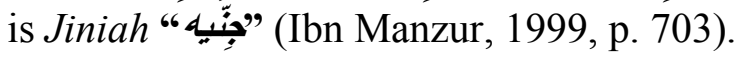

It must also be noted that there is no standard spelling in English for the word Jinn. It can be spelt 'jinn', 'jenn', 'djinn', 'djin', 'jin', 'ginn' or ' $g$ 'inn'; the plural form, meanwhile, can be transliterated as 'jnun', 'jnoun', 'djnun' or 'djnoun', 'jann' or 'jan' (Lebling, 2010). The same issue is highlighted by Caracciolo (1988) who mentions that, with reference to the various English renderings of the original Arabian Nights, "one meets a gamut of spellings such as genius, genie, genii, jinee, jinni, Jinn, djinn, ginn and, jann” (Caracciolo, 1988, p. xxviii).

Any attempt to set a clear-cut classification for Jinn, however, is doomed to lack precision and accuracy. The blurred line between these classes is caused by the "slippage in terminology" that allows Jinn to escape all kinds of categorisation simply because the terms of classification fold into each other, and each lexical item can signify more than one class (Duggan, 2016, p. 120). For example, Jinn "can be used to refer to an Efreet or a Marid (that is any evil Jinnee)" (Duggan, 2016, p. 120). This "slippage" or the "fleeting concept," as termed by El-Zein (2009), highlights the problematic process of cataloguing the classes of such supernatural creatures. This haziness creates a state of uncertainty that may affect the translator's decision in terms of what lexical item can carry the exact sense behind the word used in Arabic.

Jinns, therefore, can be a valid representative of cultural-bound lexical items that need to be scrutinised to figure out the exact meaning even by a native speaker. Such lexical items need to be thoroughly investigated before one engages in the translation process. This is due to 
the hazy borderline between the different classes of Jinn which complicates any attempt to translate them. This has even led some scholars to believe that the different translation strategies such as the "elaborate footnotes and critical framing devices" are of minor importance in rendering the meaning of Jinn, as understood by Arabs and Muslims, to modern Europeans (Colla, 2013).

Yet another issue that widens the gap between East and West is the different ways of perceiving the Jinn, and the image of the Jinn conjured by people in different cultures. Within the eastern context, Jinns are an essential part of its culture and belief system. Colla (2013), therefore, opines that any encounter with Jinn in the Arabo-Islamic context may be considered strange or startling but not magical or exotic, which contrasts sharply to the sense of the "outdated time of folk superstition and the outlandish realm of Oriental otherness" (Colla, 2013, p. 92). This different unthreatening image of the Jinn is promoted by the western filmic and television tradition (Duggan, 2016). To sum up, the Arabs generally perceive the Jinn as a troublesome and frightening creature, while the same word invokes, among westerners, the pretty image of Barbara Eden from the American television comedy series "I Dream of Jeannie" or that clown-like figure that appears in Disney's "Aladdin" (Lebling, 2010). It is, thus, clear that the problem of translating Jinn and their subclassifications stems from the issue of non-equivalence between Arabic and English.

Another reason behind studying the translation of Jinns as a cultural aspect is the significant role of Jinns in the belief system of a Muslim and the importance of accurate translation in rendering their most relative meaning and mirroring them in the belief system of the western Muslims. This can be explained by the following extract:

\footnotetext{
Although belief in the Jinn is not one of the five pillars of Islam, one can't be Muslim if he/she doesn't have faith in their existence because they are mentioned in the Qur'an and the prophetic tradition. Indeed, the Qur'anic message itself is addressed to both humans and Jinn, considered the only two intelligent species on Earth. The prophetic tradition mentions them in several instances (El-Zein, 2009, p. ix).
}

In other words, Jinns, unlike other cultural aspects, are an inherited part of the Islamic faith and must be translated with the utmost caution to establish an authentic belief system among western Muslims.

To sum up, the translation of Jinns as an essential component of the Arabic language and culture can enlighten the path of translating other Arabic cultural aspects. Studying this issue highlights the complexity of interpreting the metaphysical aspects of the source culture, emphasises the effect of the different perspectives of these aspects among the people of the source and target cultures, and stresses the importance of the accurate translation of the religious-cultural aspects of the source text to the target text readership. The issue of the translation of Jinns can possibly be dealt with using the suggested strategies.

\section{METHODOLOGY}

This study aims to examine the translation of different classes of Jinns from Arabic into English. The data of the study consists of several examples of the subtypes of Jinns from Mahfouz's novel in Arabic, Layali Alf Layla, and their counterparts in the English translation of the novel entitled Arabian Nights and Days by Denys Johnson-Davies. The Arabic source text is selected due to its fantastic magical nature that reflects the role of the Jinn in the original Arabian Nights and the Arabic-Islamic society. The novel is studied comprehensively using the appropriate explanation and classification of Jinn in order to locate the sample of the study. In other words, to facilitate the process of locating and analysing the Arabic examples, the 
different subclassifications of Jinn are carefully examined in order to understand the shades of meaning that differentiate one class from another.

To carry out the study, the items in the Arabic source texts are first extracted and listed. Since the current study is looking only at how the different classes of Jinn are translated, only selected examples are shown. It does not look at frequencies, nor does it attempt to find patterns or tendencies. Thus, the examples are selected to elaborate on the discussion. The examples discussing "Iblis" and "Marid" are the only examples found in the novel, while the examples discussing "Ifrit" and "Shaitan" are selected as representative examples to highlight the translation used in the remaining occurrences all over the novel.

After listing the examples, a contrastive analysis was conducted following James's (1980) two-step procedure of contrastive analysis, i.e., description and comparison. The use of this procedure in translation is explained in the following extract:

\begin{abstract}
In translation, this simply means first to understand the meaning of formal features of the original text and their role in the text's formation. The next step is producing an equivalent text in the target language, which requires a sound linguistic and cultural competence in that language. Both performance tasks - the analysis and text production - share the need for linguistic and extra-linguistic competence. (Chakhachiro, 2018, p. 51)
\end{abstract}

Following this, the study starts with an attempt to fully describe each example by investigating the cultural and linguistic background of the lexical items. A discussion of the meaning of the lexical item is carried out by consulting significant references such as Al-Jahiz (1965), Duggan (2016), El-Zein (2009), Ibn Manzur (1999), Lebling (2010) and Leeming (2004). The Arabic lexical items are then mapped to their counterparts in the English translation. The meaning of each corresponding item is also discussed, taking into account its cultural and linguistic background, and consulting related references such as dictionaries, encyclopedias, translations of the Quran and other specialised references.

The second step of the analysis is based on the second step of the contrastive analysis procedure, i.e. comparison. Here, a comparison between the source text and the translation is carried out to identify the relationships between the corresponding items, which in turn helps in identifying translation shifts. The analysis is conducted to identify the strategies used to overcome impediments that hinder the translation process. The analysis will therefore highlight the strategies used in translating the Arabic lexical items into English.

In the current study, Baker's (2018) taxonomy, which was first introduced in 1992 and fully developed in 2018, is employed in order to discuss the translation strategies and to investigate the relative levels of equivalence. Each example is studied in light of the strategies suggested by Baker and used by the translator in Arabian Nights and Days. In the discussion, each word is quoted with its neighbouring lexical items in order to provide enough contextual meaning of the word. A literal translation for each example is provided in order to establish the real sense of the extracts.

\title{
ANALYSIS AND DISCUSSION
}

The following discussion will focus on four different kinds of Jinns which are mentioned in the source text (ST), Layali Alf Layla. They are: (i) Ifrit, (ii) Iblis, (iii) Shaitan, and (iv) Marid. This section will also examine the strategies which are used to translate them into English in the target text (TT), Arabian Nights and Days. 
The word Ifrit is mentioned only once in the Quran, that is, in Chapter 27 (Surah An-Naml), verse 39, specifically in a story involving the prophet Solomon and the Queen of Sheba. The use of the word Ifrit in the Quran can be seen in the following:

Quranic verse

Literal translation

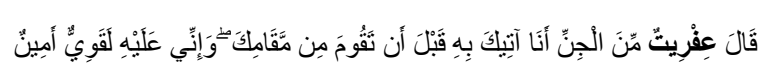
An Ifrit from the Jinn said I will bring it to you before you rise from your place, and I am strong and trustworthy for this [task].

In Al-Jahiz's book, Kitab al-Hayawan, the Ifrit is considered as a distinct class of the six classes of Jinn (Al-Jahiz, 1965). El-Zein (2009), on the other hand, argues that Ifrit refers not to a distinct type of Jinn but instead to a powerful Jinni. Either way, the entity that carries this name is generally believed to have distinct features that distinguish it from other classes of Jinn.

In the novel Arabian Nights and Days, the word Ifrit is used numerous times. Example 1 shows one of the ways the word "Ifrit" is translated, i.e. by using the word "genie".

Example 1

ST

Literal Translation

TT
Ifrit from the inhabitants of the city

A genie from among the city's dwellers. (p. 12)

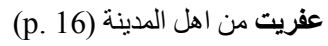

The English word "genie", which is used as an equivalent term in English for the Arabic Ifrit, is borrowed from the Arabic word Jinn (Lebling, 2010, p. xvii). It went through a long process of shifting that results in the sharp differences between the eastern and western representations of this creature, as discussed previously. This shift can be summarised as follows:

\footnotetext{
However common this figure has become, the nature of the genie has evolved considerably since the first adaptation of the Nights in Europe by Antoine Galland at the beginning of the eighteenth century. Importantly, the genie was not always so ethnically or racially defined, nor was the genie always as unthreatening as Western filmic and television traditions often present him. (Duggan, 2016, p. 114)
}

In Example 1, the translator applied the strategy of translation by cultural substitution (Baker, 2018, p. 30), presenting the word "genie" as a cultural substitute for the word "Ifrit". The word "genie" in this context does not, however, reflect the true cultural meaning of the ST, not to mention the cultural shift and distortion of the meaning between the Arabic "Jinn" and the western "genie". The effect of using the word "genie", with its western friendly and promising denotation does not reflect the terror felt by the character Sanaan Al-Gamali when he encounters the Ifrit, Qumqam. The state of horror felt by Al-Gamali, who is a central human character in the novel, crept to his wife and immediately spread to reach all the dwellers in his house. It is clearly stated in the dialogue between Al-Gamali and the Ifrit, Qumqam, that the human is intimidated by the supernatural entity. Al-Gamali was speechless, "almost vanishing in terror" (Mahfouz, 1995, p. 12). Also, the Ifrit mocked Al-Gamali's courage, saying, "What are you doing pissing yourself with fear?" (Mahfouz, 1995, p. 12).

Another issue that must be considered when analysing lexical items related to the Jinn is that one word can carry different levels of meaning. This means that a word which refers to a specific type of Jinn can, at the same time, be used within an ordinary context. Ibn Manzur (1999) furnishes in his dictionary Lisan al-Arab ('The Tongue of the Arabs') a detailed 
discussion of how the word Ifrit is used with human beings to carry negative connotations and to convey negative attributes such as malice, deception and wickedness. This is illustrated in the following example taken from Layali Alf Layla.

Example 2

ST

Literal Translation

TT
هذا هو الرجل الذي تعهد بقتله، انه سر عذابه، ووقع الاختيار عليه هو ليحرر العفريت من سحره الأسود، هو العفريت : دون سواه، نجاته رهن بالقضاء عليه. (p.29) This is the man he (the speaker) is pledged to kill. He (the governor) is the secret of his agony. $\mathrm{He}$ (the speaker) was chosen to free the Ifrit (supernatural creature) from his (the governor's) black magic. He (the governor) is the Ifrit (derogatory). His survival (the speaker) is conditioned on killing him (the governor).

: This was the man he had undertaken to kill. His heart overflowed with fear and loathing. This was the secret of his torment. It was he who had chosen to liberate the genie from his black magic. It was the genie alone who had done this. His escape was conditional on his doing away with al-Salouli. (p. 22)

In Example 2, the word Ifrit is mentioned twice. The first mention of the word Ifrit in the excerpt refers to the supernatural creature. The second of the two, however, does not refer to the supernatural being but instead to Ali al-Salouli, the corrupt governor, who enslaved the first Ifrit, Qumqam, by black magic. The speaker, Sanaan Al-Gamali, knows the truth about the governor and is aware of his corruption and suspicious cooperation with some merchants, and thus, calls him "Ifrit". By translating the second Ifrit as "genie", the negative connotation is lost.

Example 3 further illustrates the difference between Ifrit and Jinni in Arabic:

Example 3

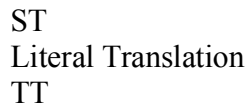

This example reflects the translator's misunderstanding of the nature of these creatures. In this example, both "Ifrit" and "Jinn" appear in the same sentence, thus underlining the unique nature of each lexical item. As shown earlier, each lexical item has a specific connotative meaning, which is unfortunately lost when the translator uses the strategy of omission. The deletion of these references and the rendering of both lexical items into one lexical item point to the translator's assumption that both words refer to the same creature. The discussion of these three examples emphasises the differences between Ifrit and Jinni in Arabic and refutes the translator's previous assumption that Ifrit and Jinni are the same and can both be rendered as "genie".

IBLIS

The following excerpt illustrates the translation of the word "Iblis "into English.

Example 4

ST

Literal Translation

TT
An idea worthy of Iblis himself.

An idea worthy of Satan himself. (p. 79)

فكرة جديرة بإبليس نفسه. (103 ) 
Many sources agree that Satan is the western equivalence of Iblis in the Islamic tradition (El-Zein, 2009; Lebling, 2010; Leeming, 2004). Iblis is defined in a well-known Arabic dictionary as "the chief of the Shaiateen, the rebellious" (Al-Mu'jam Al-Waseet, 2004, p. 3). Meanwhile, in western culture, Satan is understood as "a rebel angel who challenged the rule of God and led other angels, now fallen angels, into a like rebellion" (Partridge \& Christianson, 2014, p. 4). Therefore, the cultural substitution strategy (Baker, 2018, p. 30) adopted in the translation of "Iblis "in Example 4 managed to render the unique image of the lord of these creatures in the way that it is used in the source text. In the eighth story of Mahfouz's novel, the story of 'Nur al-Din and Dunyazad', the evil Jinni 'Sakhrabout' and his evil partner Jiniah 'Zarmabaha' expressed their admiration of the solid plan they plotted to ruin the lives of the innocent couple. The importance of their extraordinary plan is highlighted by stressing that it is not the idea of any devil but a devil with special status, i.e. "Iblis" and "Satan", as seen in Example 4. Thus, the use of "Iblis" and its equivalent, "Satan," adequately expresses this idea, which is well-established in the western and eastern heritage. The western perspective in which any devil is seen as one of "the children or servants of the chief devil, "Iblis" (Lebling, 2010, p. 8) supports the translator's choice of "Satan "as the equivalent of the "Iblis".

\section{SHAITAN}

The two most popular definitions of the word Shaitan in Arabic refer to it as either a supernatural entity or a human being. The word is defined as "an evil, seductive spirit" and also as "any corrupting rebel" (Al-Mu'jam Al-Waseet, 2004, p. 483). In other words, the word Shaitan in Islamic culture can be used to refer to a Jinn or a human being, depending on the context and the speaker's intention. This is clearly stated in the Holy Quran in Chapter 6 (Surah Al-An'am), verse 112:

Quranic verse

Literal Translation

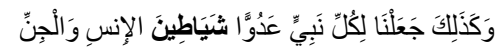
So We make for every prophet an enemy, Shaiateen from humans and Jinn.

English also makes a similar distinction, which is marked by using capitalisation to refer to different entities, as explained in the following quotation: "English also permits the plural "devils" for lesser "demons", keeping "the Devil" for Satan" (Partridge \& Christianson, 2014, p. 2). In general, the widely accepted English equivalent of the word Shaitan is "Devil" (Duggan, 2016; El-Zein, 2009). Still, a more important issue is determining the actual reference of the lexical items in both languages.

It is found that in the context of Layali Alf Layla and Arabian Nights and Days, the translator managed to overcome this issue by employing capitalisation where appropriate. More specifically, the translator used the lexical item "Devil" with a capital ' $D$ ' when the word refers to the supernatural creature, and the same lexical item but with a small ' $d$ ' when referring to human beings with demonic qualities. The following examples clarify this point.

\section{Example 5}

ST

Literal Translation

TT
I seek refuge in Allah from the accursed Shaitan.

أعوذ بالله من الثيطان الرجيم. (p.18)

The excerpt in Example 5 is a well-known Islamic phrase usually uttered before the beginning of Quran recitation and in situations in which the human being is taking refuge in Allah from the devilish power around him (Ibn Manzur, 1999, p. 499). It is, therefore, clear 
from the context that the word "Shaitan" in this utterance refers to the supernatural subclass of Jinn, which justifies the use of the capital letter in the equivalent term in the translation, i.e. "Devil". This translation can be compared with another translation of the word "Shaitan", as shown in Example 6.

Example 6

\begin{tabular}{|c|c|}
\hline ST & من مدرسة البلخي يخرج كثيرون أهل الطريق، أهل السنة كما يخر جياطين منحرفون عن الخط الأول. (49 (p) \\
\hline Literal Translation & $\begin{array}{l}\text { From the school of al-Balkhi many come out, people of the way and people of Sunnah. Also, } \\
\text { Shaiateen deviated from the first lane/path come out [from his school]. }\end{array}$ \\
\hline TT & $\begin{array}{l}\text { Many graduate from the school of al-Balkhi - people of the Way and people of the Prophet's } \\
\text { Sunna, Sufis, and Sunnis. Some devils who deviate from the path also graduate. (p. 38) }\end{array}$ \\
\hline
\end{tabular}

The source text in Example 6 makes reference to "Shaiateen", which is the plural form of "Shaitan". In this excerpt, the "Shaiateen" who graduate from al-Balkhi's school are actually human beings who rebelled against the Sultan and took actions against him. As argued by some characters in the novel, those "Shaiateen" deviate from the true path of Islam, and thus they deserve to be labelled as "Shaiateen" of humankind. Because of this, the translator adopts the use of the same equivalent but with a small 'd', i.e. "devil". In short, in these two examples, the translator managed to create different levels of meaning found in the ST by using the cultural substitution strategy (Baker, 2018, p. 30) and by paying particular attention to the role played by capitalisation in adding more shades of meaning to the TT.

MARID

Marid is used to refer to a particular class of Jinn. It is considered as "any evil Jinnee" (Duggan, 2016, p. 120). This Jinni is more vicious and malicious than Shaitan" (Al-Jahiz, 1965, p. 190). This kind of Jinn is well-known in the Islamic culture since it is mentioned in the Holy Quran as an energetic Jinn who spies on the heavens:

\begin{abstract}
In the Qur'an, the marid is an unruly force always striving to predict the future by means of astrological hearsay. The term marid is mentioned only once in the Qur'an in the following verse "We have adorned the lower heaven with the adornment of the stars and to preserve against every [rebel satan (shaytan marid)]; they listen not to the High Council, for they are pelted from every side" (Qur'an 37:7-8). (ElZein, 2009, p. 143).
\end{abstract}

In addition to describing their behaviour and attitude, El-Zein (2009) also depicts their physical appearance as giant Jinns, this feature being reported as the most prominent character of this class of Jinn in old Arabia where Marids "are visualised by Bedouins as giant demons" (Lebling, 2010, p. 117).

In English, the word "demon" is derived from the Classical Greek daimon (meaning 'spirit'). The word was originally used to refer to any good or evil spirit, but its meaning has changed with time to be "specifically applied to evil spirits, the main work of which was to frustrate, to harm, and particularly to tempt humans into sin" (Partridge \& Christianson, 2014, p. 1). Also, giants in English are known to be "enormous beings of invincible strength and terrifying appearance" (Kershaw, 1990, p. 161). The following examples indicate how such small differences between these entities can be lost in the process of translation.

Example 7

ST

Literal Translation

TT
He is still the cruel Marid.

The cruel demon. (p. 104)

ماز ال المارد القاسي. (p.136) 
The excerpt in Example 7 managed to render part of the meaning carried by the word "Marid" when it was replaced by a word related to the Jinn realm, i.e., "demon". The use of this translation strategy is clearly able to convey the cruelty and viciousness of these Jinns. It failed, however, to highlight the enormous physical appearance that distinguishes Marids from other Jinns. In spite of this, the use of the word "demon" is acceptable in this part of the novel, where the psychological features are more important than the physical characteristics in order to understand the long process of transformation of Shahryar, the bloodthirsty Sultan, who ends up abdicating the throne and wandering the desert as a poor traveller. This does not, however, change the fact that part of the original meaning is still missing. In other words, applying the strategy of translation by a related word (Baker, 2018, p. 38) may solve part of the problem, but it may also cause the loss of other significant features.

The final example further illustrates the importance of understanding the different layers of meaning in producing a more natural translation.

Example 8

ST

Literal Translation

TT
A Marid, he never saw uglier than him.

A giant more terrible than anything he had seen. (p. 227)
مارد لم ير أقبح منه. (p. 291) - مان

In this excerpt, the Arabic "Marid" is given the English equivalent of "giant". This example illustrates the use of the strategy of translation by a more neutral/less expressive word (Baker, 2018, p. 27). The translation, consequently, is able to reflect the hugeness of the "Marid" who guarded the magic door and who lifted a fully grown man "just like little bird between his hands" (Mahfouz, 1995, p. 227). The use of this strategy, however, is not able to render the specific nature of this creature. The word "giant" appears to lack this extra metaphysical layer found in the original "Marid". It must also be noted that the same word, i.e. "giant", is used to describe the enormous physical appearance of the cannibal king, who is mentioned by Sindbad in the same novel and who does not have any magical or supernatural powers (Mahfouz, 1995, p. 213).

The attempt to translate any cultural-bound lexical item is a tiresome task. This task is more complicated when the concept behind the term has different layers and interpretations within the source culture itself. The Jinn have different levels and subcategories which overlap with each other in various ways. In the case of Jinns and their classification, some argue that there is no such thing as classes or categories, but that all these different names referring to Jinn are synonyms (Marzolph, Van Leeuwen \& Wassouf, 2004, p. 535). On the other hand, the majority of scholars recognise these classes but highlight the state of uncertainty in dividing them into fixed groups.

There is a kind of polarisation between those who believe that the process of translating Jinns and their classification can benefit from the different strategies on the one hand and those who deemed it to be an impossible mission, like Colla (2013), on the other. Either way, the most critical points in the translation process can be summarised in the following three points. The first point is understanding the exact nature of the Jinni found in the source text, which enables the translator to find the most appropriate equivalent in the target language, as found in Examples 3 and 4 and discussed by Al-Jahiz (1965), El-Zein (2009), and Duggan (2016), who emphasise the fleeting concepts behind these supernatural entities in addition to the slippage in terminology when addressing "original words" (O'Neill, 2013) like the ones used with the various classes of Jinn. The second point is the idea of understanding that the names of these supernatural beings can carry different levels of meaning and may refer to other ordinary entities (not Jinn), as illustrated in Examples 1 vs. 2 and 5 vs. 6, which is the point 
that was discussed by many scholars such as Ibn Manzur (1999) and Duggan (2016). This point highlights the role of the translator as a cultural interpreter (Ivir, 2003). The third point is the importance of understanding all the details related to each of these classes by referring to the sources that pinpoint and clarify these details, for instance, Caracciolo (1988), Henninger (2017), Lebling (2010) and Leeming (2004). This understanding helps the translator to reflect on the original features and characteristics of these beings by understanding the bases of cultural differences (Jiang \& Zhuang, 2019; Li, 2019). It also ensures that the translator does not lose part of the features that distinguish each class from the other, as discussed in Example 7 and 8. In general, taking into consideration the distinctive cultural and linguistic characteristics of such culture-bound words helps in reducing the impact of non-equivalence in translation.

\section{CONCLUSION}

This study aimed at investigating the strategies used in the translation of the various classes of Jinns in the English translation of Naguib Mahfouz's novel Layali Alf Layla. The study was limited to four main subclasses of Jinn found in the novel, which are Ifrit, Shaitan, Iblis and Marid. Through the contrastive analysis carried out between the ST and the TT within the framework of Baker's taxonomy (2018), the paper demonstrated that the general concept of Jinn as a supernatural being differs significantly between the East and the West. Additionally, the different classes of Jinn do overlap, and the borders between them can be hazy even for native speakers. Thus, the image of these beings may not be established appropriately in translation.

It is noted that the denotative meaning of the Arabic lexical items related to the different classes of Jinn can easily slip from one class to another, creating a false delusion of sameness or similarity. This misunderstanding may present an inaccurate translation and consequently create a distorted scene, different from the original; the discussion, however, illustrates how a skilful translator can overcome these problems and avoid such mistakes by paying attention to the basic grammar of a language, such as capitalisation and reference.

The paper also asserted the significant role of the translator as a cultural interpreter. This role basically involves locating the cultural "original words" (O'Neill, 2013), then understanding their exact nature in the ST in order to be able to find the most appropriate equivalent in the target language which reflects the original features and characteristics, while being aware of linguistic and cultural differences between the ST and TT.

The analysis shows that when dealing with cultural-bound lexical items that have a spiritual value, the translator must be well-informed in the target language spiritual-cultural aspects. Thus, the translator can highly benefit from the cultural similarity between the two cultures, if found; otherwise, the translator can resort to the more conventional translation strategies. In this paper, the similarities between some classes of these supernatural entities can be derived from Biblical and Quranic references. Such similarities facilitate applying the appropriate translation strategies, as presented by Baker (2018).

Finally, reviewing the previous literature reveals the scarcity of academic researches tackling the translation of Jinn as a spiritual-cultural aspect that touches upon the Islamic faith and directly related to the faith of western Muslims. Accordingly, it is recommended that future studies address the issue of the translatability of various classes of Jinn in translated Islamic discourse, in particular revisiting published translations of the meanings of the Holy Quran, keeping an eye on the analysis presented in the current paper. 


\section{REFERENCES}

Al-Adwan, A., \& Abuorabialedwan, M. (2019). Handling Semantic Repetition when Translating Arabic Short Stories: The Case of Excerpt from The Book of The Dead. 3L: Language, Linguistics, Literature. 25(2), 49- 60.

Al-Jahiz, O. (1965). كتاب الحيوان[Book of Animals]. Cairo: Mustafa Alhalbi and Sons.

Al-Masri, H. (2009). Translation and Cultural Equivalence: A Study of Translation Losses in Arabic Literary Texts. Journal of Universal Language. 10(1), 7-44.

Al-Mousa, N. (1993). The Nature and Uses of the Fantastic in the Fictional World of Naguib Mahfouz. Journal of King Saud University. 5(2),105-120.

Al-Mu'jam Al-Waseet (الدعجم الوسيط) (2004). Cairo: Shorouk International Bookshop.

Allen, R. (2015). Translating Arabic Fiction. Journal of Arabic Literature. 46(2-3), 157-167.

Almanna, A. \& Farghal, M. (2015). An Emic-Etic Approach to Translating Cultural Expressions between Arabic and English. Jordan Journal of Applied Science: Humanities Sciences Series. 398(3606), 1-13.

As-Safi, A.B. (2006). Translation of Arabic Literary Works: Taha Hussein's Du'a Al-Karawan (The Call of the Curlew): A Case Study. Atlas Global Center for Studies and Research. 2, 15-22.

Bahrawi, N. (2016). A Thousand and One Rewrites: Translating Modernity in the Arabian Nights. Journal of World Literature. 1(3), 357-370.

Baker, M. (2018). In Other Words: A Coursebook on Translation. London and New York: Routledge.

Campo, J.E. (2009). Encyclopedia of Islam. New York: Infobase Publishing.

Caracciolo, P. (1988). Arabian Nights in English Literature: Studies in the Reception of the Thousand and One Nights Into. New York City: The Macmillan Press Ltd.

Chakhachiro, R. (2018). Translating Irony between English and Arabic. Cambridge: Cambridge Scholars Publishing.

Colla, E. (2013). The Porter and Portability: Figure and Narrative in the Nights. In Kennedy, P.F. \& Warner, M. (Eds.). Scheherazade's Children: Global Encounters with the Arabian Nights. (pp. 89-107). New York: New York University Press.

Dickins, J., Hervey, S. \& Higgins, I. (2017). Thinking Arabic Translation: A Course in Translation Method: Arabic to English. London and New York: Routledge.

Duggan, A. (2016). From Genie to Efreet Fantastic Apparitions in the Tales of The Arabian Nights. Journal of The Fantastic in the Arts. 27(1), 113-135.

El-Enany, R. (2005). Naguib Mahfouz the Pursuit of Meaning. London \& New York: Routledge.

El-Zein, A. (2009). Islam, Arabs, and the Intelligent World of the Jinn. New York: Syracuse University Press.

Guessabi, F. (2013). The Cultural Problems in Translating a Novel from Arabic to English Language A Case Study: the Algerian Novel. Arab World English Journal. 2, 224-232.

Hallengren, A. (2004). Nobel Laureates in Search of Identity and Integrity: Voices of Different Cultures. New Jersey: World Scientific.

Henninger, J. (2017). Pre-Islamic Bedouin Religion. In Peters, F.E. (Ed.). The Arabs and Arabia on the Eve of Islam. (pp. 109-128). London and New York: Routledge.

Ibn Manzur, M. (1999). بسان العرب [the Tongue of the Arabs]. Beirut: Dar Ehia Al-Tourath Al-Arabi.

Ismail, O. \& Ramadan, L. (2012). The Jinn as equivalent to evil in 20th Century Arabian Nights and Days. In Hendrix, S.E. \& Shannon, T.J. (Eds.). Magic \& the Supernatural. (pp. 15-20). Oxford: Inter-Disciplinary Press.

Ivir, V. (2003). Translation of Culture and Culture of Translation. Studia Romanica et Anglica Zagrabiensia: Revue Publiée par les Sections Romane, Italienne et Anglaise de la Faculté des Lettres de l'Université de Zagreb. 47, 117-126.

James, C. (1980). Contrastive Analysis. London: Longman.

Jiang, L. \& Zhuang, Y. (2019). Non-equivalence in Legal Translation. Theory and Practice in Language Studies. $9(12), 1630-1634$.

Johnson-Davies, D. (2006). Memories in Translation: A Life Between the Lines of Arabic Literature. Cairo: The American University in Cairo Press.

Joshi, S.Y. (2007). Icons of Horror and the Supernatural. London: Greenwood Press.

Kershaw, S. (1990). A Concise Dictionary of Classical Mythology. London: Basil Blackwell.

Klankert, T. (2014). Strange Relations: Cultural Translation of Noh Theatre in Ezra Pound's Dance Poems and WB Yeats's At the Hawk's Well. Word and Text, A Journal of Literary Studies and Linguistics. 4(2), 98111.

Kuhiwczak, P. (2003). The Troubled Identity of Literary Translation. In Anderman, G. \& Rogers, M. (Eds.). Translation Today: Trends and Perspectives. (pp. 112-124). Clevedon: Multilingual Matters.

Lebling, R. (2010). Legends of the Fire Spirits: Jinn and Genies from Arabia to Zanzibar. London: Bloomsbury Publishing. 
Leeming, D. (2004). Jealous Gods and Chosen People: The Mythology of the Middle East. Oxford: Oxford University Press.

Li, R. (2019). On the Influence of Cultural Differences on the Translation of British and American Literature. Advances in Higher Education. 3(2), 75-78.

Lomas, T. (2018). Translating Happiness: A Cross-Cultural Lexicon of Well-Being. Cambridge: MIT Press.

Mahfouz, N. (1979) ليالي الف ليلة]Nights of the Thousand Nights]. Cairo: Maktabt Misr.

Mahfouz, N. (1995). Arabian Nights and Days (tr. D. Johnson-Davies). Cairo: The American University in Cairo Press.

Marzolph U., Van Leeuwen R. \& Wassouf, H. (2004). The Arabian Nights: An Encyclopedia. California: AbcClio.

Muhaidat, F. \& Neimneh, S. (2011). Translators as Intercultural Mediators: Translating Religious Expressions in Naguib Mahfouz's Palace of Desire into English. Higher Education of Social Science. 1(1), 14-23.

O’Neill, S.P. (2013). Translating Oral Literature in Indigenous Societies: Ethnic Aesthetic Performances in Multicultural and Multilingual Settings. Journal of Folklore Research: An International Journal of Folklore and Ethnomusicology. 50(1-3), 217-250.

Partridge, C.H. \& Christianson, E.S. (2014). The Lure of the Dark Side: Satan and Western Demonology in Popular Culture. London and New York: Routledge.

Peterson, M.A. (2007). From Jinn to Genies: Intertextuality, Media, and the Making of Global Folklore. In Sherman, S.R. \& Koven, M.J. (Eds.). Folklore/Cinema: Popular Film as Vernacular Culture. (pp. 93112). Utah: Utah State University Press.

Pym, A. (2010). Exploring Translation Theories. London and New York: Routledge.

Suliman, A., Md Yunus, M., \& Mohd Nor, M.Y. (2019). Scrutinising the preferences in literature approaches and activities: From the lenses of ESL teachers. 3L: Language, Linguistics, Literature. 25(2), 38- 48.

Tarigan, F.N. \& Juliana, J. (2019). Non-Equivalence at Scientific Terms in Mathematics Bilingual Textbook. SALTeL Journal (Southeast Asia Language Teaching and Learning). 2(1), 50-56. 